\title{
The effects of a Cognitive Stimulation Therapy [CST] programme for people with dementia on family caregivers' health
}

\author{
Elisa Aguirre ${ }^{1,2^{*}}$, Zoe Hoare ${ }^{3}$, Aimee Spector ${ }^{4}$, Robert T Woods ${ }^{5}$ and Martin Orrell ${ }^{1,2}$
}

\begin{abstract}
Background: There is growing evidence that Cognitive Simulation Therapy (CST) benefits cognition and quality of life of people with dementia, but little is known about the indirect effects of this intervention on family caregivers. This study sought to investigate the effect of CST on family caregivers general health status of people with dementia living in the community attending the CST intervention.
\end{abstract}

Method: Eighty-five family caregivers of people with dementia took part in the study. All the people with dementia received the standard twice weekly seven weeks of the CST intervention plus either 24 weeks of a maintenance CST (MCST) intervention or 24 weeks of treatment as usual. Family caregivers were assessed before and after their relatives the CST programme, and after 3 and 6 months of the MCST programme. A pre and post CST groups comparison was undertaken to evaluate the open trial first phase and an ANCOVA model used to analyse the maintenance phase with its controlled comparison.

Results: We found no evidence for a benefit on the family caregiver outcome measures of the intervention before and after CST groups by using a t-test analysis or any significant differences between intervention and control groups for any of the variables considered at any time point ( 3 and 6 month follow up).

Conclusion: CST seems to have a relatively specific benefit fpr people with dementia that may not carry over to family carers. Future studies need to further explore and compare the effects that CST might bring to family caregivers of people with dementia attending the intervention.

Trial registration: Current Controlled Trials ISRCTN26286067

Keywords: Dementia, Alzheimer's disease, Family caregivers, Cognitive stimulation, Quality of life

\section{Background}

It has been estimated that currently 35.6 million people live with dementia and this number will increase in 2050 by 115.4 million [1]. The majority of people with dementia are cared for at home and looked after by a member of the family or close friend [2] and therefore, as the number of people with dementia increases so will the number of family caregivers. Being a carer for people with dementia has been associated with frequent use of medication and increased visits to health professionals

\footnotetext{
*Correspondence: e.aguirre@ucl.ac.uk

1 Unit of Mental Health Sciences, University College London, Charles Bell House, 67-73 Riding House Street, London W1W 7EJ, England ${ }^{2}$ Research and Development Department, North East London Foundation Trust, Goodmayes Hospital, Barley Lane, Ifford, Essex, England Full list of author information is available at the end of the article
}

$[3,4]$, as well as with poor clinical outcomes such as depression, illness and decreased quality of life [5]. Dementia caregiving has also been linked with poor outcomes for people with dementia such as poor quality of life and increased risk of nursing home placement [6,7].

Systematic reviews have found cognitive stimulation to be a psychosocial intervention for people with dementia [1,8-10], which has robust evidence. Cognitive stimulation programmes target cognition but have a social element usually in a group or with the family caregiver, and the included cognitive activities do not primarily consist of practice on specific cognitive modalities [11].

Evidence in relation to its effectiveness on family caregiver outcome measures is less conclusive. The Cochrane review found only three studies reporting on 
family caregivers outcomes and in these studies [12-14], no differences were noted and the effect sizes for anxiety, depression and caregiver burden were close to zero, indicating no likely differences in caregiver outcomes [10]. In one study [12], the family caregivers were trained to deliver the intervention, without showing any adverse effect on them [10].

Generally the effectiveness of interventions has been judged in relation to how far the specific outcomes relate to the specific person targeted (person with dementia or family caregiver). However, there is little evidence as to whether interventions targeted at people with dementia might benefit carers. So far the dominant conceptual model for caregiving is the stress-coping model [15] that assumes that the onset and progression of chronic illness and physical disability are stressful for both the person with dementia and the family caregiver [15]. Therefore, under this framework, it is expected that CST by increasing the person with dementia's cognitive abilities and well being, may lead to an improvement in family caregivers mood and wellbeing.

The aim of this study is to examine the impact on the family caregivers of the CST programme for people with dementia.

\section{Methods}

\section{Participants}

Participants were family caregivers of people with dementia living in the community who were taking part in a large randomised control trial of Maintenance CST (MCST) for dementia [16,17]. Ethical approval was obtained through the Multi-centre Research Ethics Committee (ref no. 08/H0702/68). The clinical trial is registered ISRCTN26286067. Family caregivers were recruited from
January 2009 till September 2010 in community settings in London, Essex and Bedfordshire. Family caregivers were referred by the manager from the day centre or community mental health team where the CST trial groups were taking place. Family caregivers were contacted and invited for a meeting where the purpose of the trial was explained and if consented were recruited with their relatives for the study.

\section{Design}

People with dementia received standard CST which is a seven-week 14-session group psychosocial treatment for dementia that is effective in improving cognition and quality of life [18]. They were then randomised into either [a] the maintenance CST programme once weekly for 24 weeks or [b] treatment as usual [17] (Figure 1). Assessments of the family caregivers were conducted in the week prior to and following their relatives participation in the standard CST intervention, and at three and six month follow up after randomisation into the maintenance programme group or treatment as usual.

\section{Intervention}

The intervention included the standard CST programme, 14-sessions run twice weekly $[19,20]$ followed by the Maintenance CST programme $[21,22]$ or treatment as usual. The intervention was based on the theory of cognitive stimulation as applied to the original CST programme [19] guided by the MRC framework [23] for complex interventions. The complete CST and Mainteance CST programme, incorporated the use of an "RO board", displaying both personal and orientation information, including the group name (as

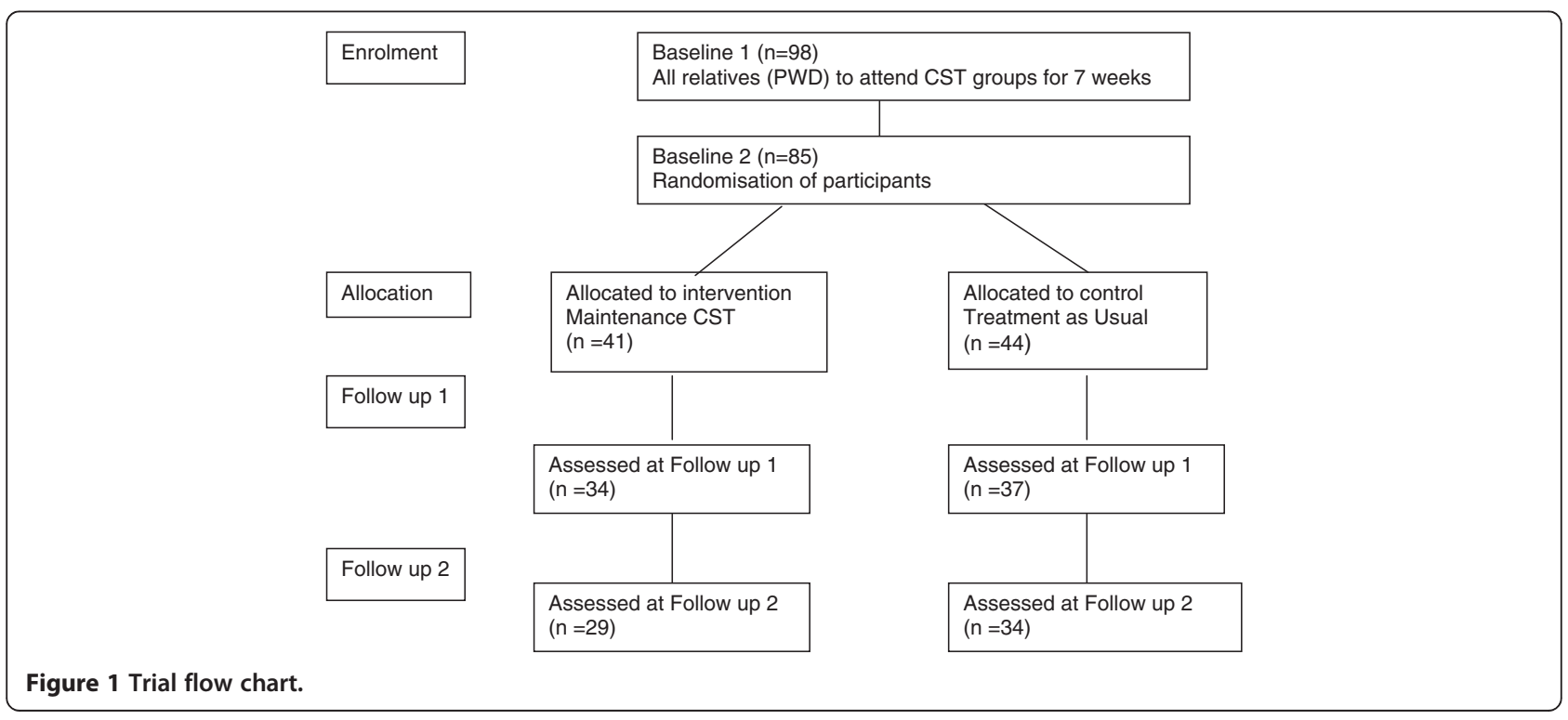




\begin{tabular}{ll} 
Table $\mathbf{1}$ Sociodemographic characteristics at baseline \\
$\mathbf{1}$ (n=98) \\
\hline Characteristics \\
\hline Relationship to PWD at BL1 - \\
Spouse & $44(45 \%)$ \\
Child/niece/nephew) & $47(48 \%)$ \\
Brother/sister & $2(2 \%)$ \\
Friend & $3(3 \%)$ \\
Other (Grand-daughter, Warden) & $2(2 \%)$ \\
Carer living situation & $55 \%$ Lives in \\
Type of dementia & \\
Alzheimer's type & $45(46 \%)$ \\
Vascular type & $16(16 \%)$ \\
Other & $15(15 \%)$ \\
Not known & $20(20 \%)$ \\
Missing & $2(2 \%)$ \\
Carer employment status & 26 retired \\
& 28 employed \\
& 5 unemployed \\
& 3 housewife/husband \\
& 36 missing \\
\hline
\end{tabular}

chosen by participants). The guiding principles of the intervention involved using new ideas, thoughts and associations; using orientation sensitively and implicitly; a focus on opinions rather than facts; using reminiscence as an aid to the here-and-now; providing triggers to aid recall; creation of continuity and consistency between sessions; focus on implicit (rather than explicit) learning; stimulating language; stimulating executive functioning and being person-centred (treating people as unique individuals with their own personality and preferences). Each group had two facilitators, one from the research team and a co-facilitator who was a member of staff from the recruited centre (e.g. residential care home). The use of two facilitators for each group enabled effective de-briefing and reflection to occur at the end of each session.

\section{Assessment measures}

EQ-5D

EQ-5D [24] is a standardized instrument for use as a measure of health outcome. Applicable to a wide range of health conditions and treatments, it provides a simple descriptive profile and a single index value for health status. EQ-5D was originally designed to complement other instruments but is now increasingly used as a 'stand alone' measure. EQ-5D is designed for selfcompletion by respondents, and is easy, taking only a few minutes to complete. Instructions for family caregivers to follow were included in the questionnaire. The scale includes a 3 - level $(1=$ no problem, $2=$ moderate problem, 3 = severe problem), 5-dimensional format and the Visual Analogue Scale [VAS] with a maximum score of 100 indicating the best health status.

\section{SF-12}

The Short Form-12 UK [25] Health Survey measures generic health concepts relevant across age, disease, and treatment groups. It provides a comprehensive, psychometrically sound, and efficient way to measure health from the patient's point of view by scoring standardized responses to standard questions. The SF-12 includes 8 concepts commonly represented in health surveys: physical functioning, role functioning physical, bodily pain, general health, vitality, social functioning, role functioning emotional, and mental health.

\section{Analysis}

For the before and after CST data the analysis followed a paired sample t-test analysis. For the maintenance CST or treatment as usual phase, an ANCOVA model was fitted for each of the follow up time points. The ANCOVA model incorporated centre as a random factor and baseline 2 score (post CST) as a covariate.

\section{Results}

Tables 1 and 2 presents baseline data before and after the CST groups on sociodemographic and service use variables. Generally participants were female $(n=84$;

Table 2 Sociodemographic characteristics at baseline 2 $(n=85)$ divided by trial arm

\begin{tabular}{lllll}
\hline & & MCST & TAU & Total \\
\hline Relationship to PwD & Spouse & 19 & 23 & 42 \\
at BL1 & Child (inc. niece/nephew) & 21 & 17 & 38 \\
& Brother/Sister & 0 & 2 & 2 \\
& Friend & 0 & 1 & 1 \\
& Other (Grand-daughter, & 1 & 1 & 2 \\
& Warden) & & & \\
& Lives with & 24 & 26 & 50 \\
& Doesn't live with & 17 & 18 & 35 \\
& Alzheimer's type & 12 & 25 & 37 \\
& Vascular type & 8 & 4 & 12 \\
& Other & 10 & 5 & 15 \\
& Not known & 9 & 10 & 19 \\
& Missing & 1 & 1 & 2 \\
& Retired & 7 & 19 & 26 \\
& Employed & 12 & 10 & 22 \\
& Unemployed & 4 & 1 & 5 \\
& Housewife/Househusband & 0 & 1 & 1 \\
& Missing & 13 & 15 & 28 \\
\hline
\end{tabular}


Table 3 Family caregiver outcomes before and after CST (Baseline 1 to Baseline 2)

\begin{tabular}{llllllll}
\hline Measure & $\mathbf{n}$ for CC & Before CST mean (SE) & After CST mean (SE) & Difference & t value & p value & Effect size \\
\hline SF-12b PCS & 85 & $38.14(6.39)$ & $38.84(6.31)$ & $0.70(6.01)$ & 1.071 & .29 & 0.12 \\
SF-12 MCS & 85 & $42.25(5.25)$ & $42.33(5.13)$ & $0.08(5.62)$ & 0.134 & .89 & 0.01 \\
EQ-5Db Utility & 82 & $0.82(.21)$ & $0.84(0.21)$ & $0.02(.205)$ & 0.78 & .44 & 0.08 \\
EQ-5Db VAS & 82 & $71.73(16.85)$ & $74.61(18.26)$ & $2.87(16.08)$ & 1.62 & .11 & 0.18 \\
\hline
\end{tabular}

$86 \%)$, above retirement age, married to the person with dementia $(n=44 ; 45 \%)$ or son/daughters $(n=47 ; 48 \%)$. Almost all were providing daily assistance to people with a diagnosis of Alzheimer's type of dementia ( $n=45 ; 46 \%$ ). The mean age of the people with dementia was at 81 [range 52-97] years. Overall retention was good. We followed up 71 (83.5\%) participants at 3 months and 63 (74.1\%) at six months.

Table 3 shows the analysis of the first phase of the study. There was no evidence for a benefit of intervention immediately after the standard CST group programme on the family caregiver outcome measures. Table 4 shows the analyses of the ANCOVA for the Maintenance stage of the programme. Again, we found no evidence of any significant differences between groups for any of the variables considered at any time point. [3 and 6 month follow up].

\section{Discussion}

This study evaluated the potential indirect effects of CST on the family caregivers general health status and quality of life. The standard twice weekly for seven weeks CST intervention showed benefits to cognition and quality of life for people with dementia [18] and the maintenance programme showed to benefit quality of life of people with dementia at 6 months [19] and cognition for people on cholinesterase inhibitors [19]. However, we found no evidence for a benefit on the family caregiver outcome measures.

The external validity of this trial is high though two aspects limit its generalisability, lack of ethnic mix and wide geographical spread. Participants were almost exclusively white British and therefore we cannot draw conclusions on the effectiveness of this intervention for other ethnical backgrounds or cultures. In addition, it may be that an effect would be found with a larger numbers of family carers.
Research so far suggests two basic types of interventions to help and support people caring for a relative or a friend with dementia. These range from those [a] providing direct practical assistance with care by the provision of respite care, to [b] interventions directly delivered to family caregivers by offering psycho educational or psychosocial support. Non-cognitive features of dementia are most likely to be associated with psychological problems in caregivers [26]. The stress/health model as the dominant theoretical model guiding the design of caregiver interventions, assumes that the severity of dementia is one of the primary stressors on the caregiver [27]. Thus, our study hypothesized that if CST can improve cognitive abilities and increase their quality of life, this effect could potentially have a beneficial effect on family caregivers. As the perceived health of the family caregivers is not only related to cognitive impairment of the person with dementia, but also to the behavioural and psychological symptoms in dementia [26], further studies should include these variables in their analysis when evaluating further the indirect effect of this intervention.

Different types of interventions for people with dementia may be more or less effective depending upon the nature of the relationship between the caregiver and the care recipient. It might be that a cognitive based intervention delivered by a family caregiver such as individualized CST [28] might be of greater success in positively influencing both partners. In a pilot study, Moniz-Cook et al. [29] found that a home-based memory management programme involving the family carer led to improvements in memory in the person with dementia, improvements in carer wellbeing, and a reduction in care home admissions at 18 months follow-up. Similarly benefits in cognition in people with dementia and carer wellbeing have been reported in studies by Quayhagen et al. [30].

Table 4 Effects of Maintenance CST on adjusted complete case (CC) outcomes at primary and secondary end points

\begin{tabular}{|c|c|c|c|c|c|c|c|c|c|c|}
\hline \multirow[b]{3}{*}{ Adjusted outcomes } & \multicolumn{5}{|c|}{ FU1- 3 month follow up } & \multicolumn{5}{|c|}{ FU2- 6 month follow up } \\
\hline & \multicolumn{2}{|c|}{ Treatment } & \multirow{2}{*}{$\begin{array}{l}\text { Control } \\
\text { Mean (SE) }\end{array}$} & \multirow{2}{*}{$\begin{array}{l}\text { Difference } \\
\text { Mean (SE) }\end{array}$} & \multirow[t]{2}{*}{ p value } & \multicolumn{2}{|c|}{ Treatment } & \multirow{2}{*}{$\begin{array}{l}\text { Control } \\
\text { Mean (SE) }\end{array}$} & \multirow{2}{*}{$\begin{array}{l}\text { Difference } \\
\text { Mean (SE) }\end{array}$} & \multirow[t]{2}{*}{$p$ value } \\
\hline & $\mathrm{n}$ & Mean (SE) & & & & $n$ & Mean (SE) & & & \\
\hline SF-12 PCS & 71 & $39.07(0.93)$ & $39.26(0.97)$ & 0.19 (1.34) & .89 & 63 & $37.89(0.94)$ & $38.44(1.02)$ & 0.55 (1.39) & .70 \\
\hline SF-12 MCS & 71 & $42.43(0.76)$ & $43.04(0.80)$ & $0.61(1.11)$ & .58 & 63 & $41.88(0.85)$ & $42.91(0.92)$ & $1.03(1.26)$ & .42 \\
\hline EQ-5D Utility & 70 & $0.83(0.02)$ & $0.81(0.02)$ & $-0.02(0.03)$ & .52 & 63 & $0.79(0.02)$ & $0.84(0.02)$ & $0.05(0.03)$ & .12 \\
\hline EQ-5D VAS & 70 & $75.86(2.05)$ & $74.04(2.17)$ & $-1.82(2.99)$ & .57 & 63 & $74.41(2.33)$ & $72.28(2.52)$ & $-2.14(3.43)$ & .54 \\
\hline
\end{tabular}




\section{Conclusions}

Group CST interventions benefit people with dementia but there is little evidence to suggest that they may be beneficial for family caregivers. Conclusions from this study are only preliminary and therefore further studies need to improve the methodological qualities of this type of study, for instance, increasing sample size and measuring a wider range of family caregivers outcomes (eg. burden, knowledge, anxiety, depression, quality of life). Further studies could also explore the impact of individual CST on different family caregiver outcomes.

\section{Competing interest}

AS runs the CST training course on a commercial basis. EA, AS, BW and MO have co-authored the CST and Maintenance CST manual, the royalties from which are received by the Dementia Services Development Centre Wales.

\section{Authors' contributions}

All authors participated and contributed to design and conduct of the SHIELD-Maintenance CST trial and commented on drafts, read and approved the final manuscript. EA lead the writing of this paper and wrote the first draft of the presented manuscript, implemented the design and overall organisation of the trial; managed the development of the programme; recruited all centres that took part in the trial; recruited and assessed participants and ran some of the intervention groups. ZH was trial statistician and led data management and analysis of the trial. AS was a co-applicant and provided clinical supervision for the researchers running the intervention and contributed to the theory behind the trial. RTW was co-applicant and principal investigator for clinical psychology. MO was principal applicant and chief investigator; he led the design and execution the trial.

\section{Acknowledgements}

Maintenance Cognitive Stimulation Programme (ISRCTN26286067) is part of the Support at Home-Interventions to Enhance Life in Dementia (SHIELD) project (Application No. RP-PG-0606-1083) awarded to Prof. Orrell (UCL/ NELFT), based in North East London Foundation Trust, and funded by the NIHR Programme Grants for Applied Research funding scheme. Other grant holders include Woods (Bangor), Challis (Manchester), Moniz-Cook (Hull), Russell (Swansea), Knapp (LSE) and Dr Charlesworth (UCL).

This report/article presents independent research commissioned by the National Institute for Health Research (NIHR) under its Programme Grants for Applied Research scheme (RP-PG-060-1083). The views expressed in this publication are those of the authors and not necessarily those of the NHS, the NIHR or the Department of Health.

\section{Author details}

${ }^{1}$ Unit of Mental Health Sciences, University College London, Charles Bell House, 67-73 Riding House Street, London W1W 7EJ, England. ${ }^{2}$ Research and Development Department, North East London Foundation Trust, Goodmayes Hospital, Barley Lane, Ilford, Essex, England. ${ }^{3}$ North Wales Organisation for Randomised Trials in Health [NWORTH], Institute of Medical \& Social Care Research, Bangor, Wales. ${ }^{4}$ Research Department of Clinical, Educational and Health Psychology, University College London, 1-19 Torrington Place, London WC1E 7HB, England. ${ }^{5}$ DSDC Wales, Bangor University, 45 College Road, Bangor, Gwynedd LL57 2AS, Wales.

Received: 10 July 2013 Accepted: 18 February 2014

Published: 14 March 2014

\section{References}

1. Prince M, Bryce R, Ferri C: World Alzheimer report: the benefits of early diagnosis and intervention. Alzheimer's Disease International; 2011. www.alz.co.uk/worldreport2011.

2. Van Mierlo LD, Meiland FJ, Van der Roest HG, Dröes RM: Personalised caregiver support: effectiveness of psychosocial interventions in subgroups of caregivers of people with dementia. Int J Geriatr Psychiatry 2012, 27(1):1-14
3. Pot AM, Deeg DJH, Van Dyck R: Psychological well-being of informal caregivers of elderly people with dementia: changes over time. Aging Ment Health 1997, 1(3):261-268.

4. Eagles JM, Craig A, Rawlinson F, Restall DB, Beattie JA, Besson JA: The psychological well-being of supporters of the demented elderly. $\mathrm{Br} J$ Psychiatry 1987, 150(3):293-298.

5. Schulz R, Boeerner K, Shear K, Zhang S, Gitlin L: Predictors of complicated grief among dementia caregivers: A prospective study of bereavement. Am Assoc Geriatr Psychiatry 2006, 14(8):650-658.

6. Gaugler JE, Kane RL, Kane RA, Newcomer R: Unmet care needs and key outcomes in dementia. J Am Geriatr Soc 2005, 53:2098-2105.

7. Yaffe K, Fox P, Newcomer R, Sands L, Lindquist K, Dane K, Covinsky KE: Patient and caregiver characteristics and nursing home placement in patients with dementia. JAMA 2002, 287(16):2090-2097.

8. Olazaran J, Reisberg B, Clare L, Cruz I, Pena-Casanova J, Del Ser T, Woods RT, Beck C, Auer S, Lai C, Spector A, Fazio S, Bond J, Kivipelto M, Brodaty H, Rojo JM, Collins H, Teri L, Mittelman M, Orrell M, Feldman HH, Muniz R: Nonpharmacological therapies in Alzheimer's disease: a systematic review of efficacy. Dement Geriatr Cogn Disord 2010, 30(2):161-178.

9. Livingston G, Johnston K, Katona C, Paton J, Lykestsos CG: Systematic review of psychological approaches to the management of neuropsychiatric symptoms of dementia. Am J Psychiatry 2005, 162(11):1996-2021.

10. Woods B, Aguirre E, Spector A, Orrell M: Cognitive stimulation to improve cognitive functioning in people with dementia. Cochrane Database Syst Rev 2012(Issue 2):Art. No.: CD005562. doi:10.1002/14651858.CD005562. pub2.14.

11. Clare L, Woods RT: Cognitive training and cognitive rehabilitation for people with early-stage Alzheimer's disease: a review. Neuropsychol Rehabil 2004, 14:385-401.

12. Onder G, Zanetti O, Giacobini E, Frisoni GB, Bartorelli L, Carbone G, Lambertucci P, Silveri MC, Bernabei R: Reality orientation therapy combined with cholinesterase inhibitors in Alzheimer's disease: randomised controlled trial. Br J Psychiatry 2005, 187:450-455.

13. Bottino CMC, Carvalho IAM, Alvarez AM, Avila R, Zukauskas PR, Bustamante SEZ, Andrade FC, Hototian SR, Saffi F, Camargo CHP: Cognitive rehabilitation combined with drug treatment in Alzheimer's disease patients: a pilot study. Clin Rehabil 2005, 19:861-869.

14. Spector A, Orrell M, Davies S, Woods B: Can reality orientation be rehabilitated? Development and piloting of an evidence-based programme of cognition-based therapies for people with dementia. Neuropsychol Rehabil 2001, 11(3-4):377-397.

15. Schulz R, Sherwood P: Physical and Mental Health Effects of Family Caregiveing. Am J Nurs 2008, 108(9 Suppl):23-27. doi:10.1097/01. NAJ.0000336406.45248.4C.

16. Aguirre E, Spector A, Hoe J, Russell TI, Knapp M, Woods TR, Orrell M: Maintenance Cognitive Stimulation Therapy (CST) for dementia: a singleblind, multi-centre, randomized controlled trial of Maintenance CST vs. CST for dementia. Trials 2010, 11:46.

17. Orrell M, Aguirre E, Spector A, Hoare Z, Streater A, Woods B, Streater A, Donovan H, Hoe J, Russell I: Maintenance Cognitive Stimulation Therapy (CST) for dementia: a single-blind, multi-centre, randomized controlled trial of Maintenance CST vs. CST for dementia. BMJ 2014. in press.

18. Aguirre E, Hoare Z, Streater A, Spector A, Woods B, Hoe J, Orrell M: Cognitive Stimulation Therapy (CST) for people with dementia- who benefits most? Int J Geriatr Psychiatry 2012. doi:10.1002/gps.3823.20 Aguirre et al., 2011.

19. Spector A, Thorgrimsen L, Woods B, Royan L, Davies S, Butterworth M, Orrell M: Efficacy of an evidence-based cognitive stimulation therapy programme for people with dementia: randomised controlled trial. $\mathrm{Br} J$ Psychiatry 2003, 183:248-254.

20. Spector A, Thorgrimsen L, Woods B, Orrell M: Making a difference: an evidence-based group programme to offer cognitive stimulation therapy (CST) to people with dementia: manual for group leaders. UK: Hawker Publications; 2006.

21. Aguirre E, Spector A, Hoe J, Streater A, Russell IT, Woods RT, Orrell M: Development of an evidence- based extended programme of maintenance cognitive stimulation therapy (CST) for people with dementia. Non-pharmacological Therapies in Dementia Journal 2011, 1(3):198-215.23

22. Aguirre E, Spector A, Streater A, Hoe J, Woods B, Orrell M: Making a Difference 2: volume two: an evidence based group programme to offer Maintenance Cognitive Stimulation Therapy (CST) to people with dementia. UK: Hawker Publications; 2011. 
23. Craig P, Dieppe P, Macintyre S, Michie S, Nazareth I, Petticrew M: Developing and evaluating complex interventions: the new Medical Research Council guidance. BMJ 2008, 337:a1655.

24. The EG: EuroQol-a new facility for the measurement of health-related quality of life. Health Policy 1990, 16(3):199-208.

25. Jenkinson C, Layte R: Development and testing of the UK SF-12 (short form health survey). J Health Serv Res Policy 1997, 2(1):14.

26. Donaldson $\mathrm{C}$, Tarrier $\mathrm{N}$, Burns $\mathrm{A}$ : The impact of the symptoms of dementia on caregivers. Br J Psychiatry 1997, 170(1):62-68.27.

27. Schulz R, O'Brien AT, Bookwala J, Fleissner K: Psychiatric and physical morbidity effects of dementia caregiving: prevalence, correlates, and causes. Gerontologist 1995, 35(6):771-791.

28. Orrell M, Woods B, Spector A: Should we use cognitive stimulation therapy to improve cognitive function in people with dementia. BMJ 2012, 344:e633. doi:10.1136/bmj.e633.

29. Moniz-Cook E, Agar S, Silver M, Woods R, Wang M, Elston C, Win T: Can staff training reduce behavioural problems in residential care for the elderly mentally ill? Int J Geriatr Psychiatry 1998, 13(3):149-158.

30. Quayhagen MP, Quayhagen M, Corbeil RR, Hendrix RC, Jackson JE, Snyder L, Bower D: Coping with dementia: evaluation of four nonpharmacologic interventions. Int Psychogeriatr 2000, 12(2):249-265.

doi:10.1186/1471-2318-14-31

Cite this article as: Aguirre et al:: The effects of a Cognitive Stimulation

Therapy [CST] programme for people with dementia on family caregivers' health. BMC Geriatrics 2014 14:31.

\section{Submit your next manuscript to BioMed Central and take full advantage of:}

- Convenient online submission

- Thorough peer review

- No space constraints or color figure charges

- Immediate publication on acceptance

- Inclusion in PubMed, CAS, Scopus and Google Scholar

- Research which is freely available for redistribution 